\title{
Energy Usage Solution of OLSR in Different ENVIRONMENT
}

\author{
Suhazlan Suhaimi ${ }^{1}$ and Kamaruddin Mamat ${ }^{2}$ \\ ${ }^{1}$ Sultan Idris Education University, Tanjong Malim, Perak, Malaysia \\ ${ }^{2}$ Universiti Teknologi Mara, Shah Alam, Selangor, Malaysia \\ ABSTRACT \\ One of the main issues in deploying the MANET scenario using simulation tools is how to adapt the \\ MANET protocol setting to network scenarios such as the suitable number of mobile devices (number of \\ nodes), network space area, data transmission rate, and the node mobility speed. This issue of adaption \\ represents an important focus of research because, thus far, MANET protocol only works with fixed \\ network settings, which may not be suitable in certain network scenarios. Premised on this critical \\ situation, the main objective of this research is to implement the simulation scenario for the Ad hoc network \\ using OLSR routing protocol. Once implemented, the energy usage and node keep alive of this Ad hoc \\ network were tested and analyzed.
}

\section{KEYWORDS}

MANET, OLSR, Simulation, Energy Saving System, Routing Protocol.

\section{INTRODUCTION}

There are two types of wireless networks, namely infrastructure and ad hoc networks. With infrastructure networks, each node only communicates with the base station that provides internodes routing and fixed network connectivity. For ad hoc networks, every node communicates with other nodes directly or indirectly through intermediate nodes that relay its packets due to the limitation of transmission power [1]. The ad hoc networks can be further categorized into two types, namely static ad hoc networks and mobile ad hoc networks (or famously known as MANET). As the name suggests, MANET [2,3] supports mobility among all the nodes in the networks. Against this backdrop, this thesis emphasizes on the adaptability of MANET with various network scenarios. MANET can be described as a group of mobile nodes that communicate with each other without using any fixed network infrastructure or access point to transmit data. Given this flexibility, this network can be easily deployed in rural areas, battlefields or disaster recovery mission sites (e.g., floods, earthquakes and landslides areas) [2].The first issue of the MANET is how to deploy this type of network in the real situation. The Ad hoc network should be set up first before implementing the MANET network. After completing the network setup of the Ad hoc network, the network was tested and the data were collected to analyze the capability of the full network setup. Then, the study was continued to examine the energy usage based on this network, particularly by examining the method to enhance the energy usage in simulation scenario [4,5]. A matrix solution table was developed, and the related data of energy usage and node keep alive were collected and analyzed.

\section{OLSR SIMULATION SCENARIO}

MANET can be deployed in a wide range of scenarios, with widely differing network characteristics, such as network size, topology, node density, mobility and connectivity pattern, 
traffic pattern, and others. There is no single routing protocol that can perform optimally in all these situations. In addition, these networks are often dynamic, and their characteristics can evolve significantly over time. This section explores how the choice of protocol mechanisms and protocol parameters impacts on the network performance for a range of MANET scenarios. The discussion begins with the High_Mobility_Speed Scenario, followed by High_Data_Tranmission_Rate Scenario.

\subsection{High_Mobility_Speed Scenario}

High_Mobility_Speed Scenario refers to the scenario which was set up using high mobility speed (22.2 meter/sec) while High_Data_Tranmission_Rate Scenario was set up using high data transmission rate (45.0 packets per sec). Both scenarios consists of several cases which are differentiated with different size of network space (i.e. 400X400 unit, 600X600 unit 800x800 unit, and 1000X1000 unit). The results were elaborated based on how the elements, for example, the number of nodes, size of network space area, data transmission rate, and mobility speed influenced the energy usage, and the number of nodes keeps alive. Our discussion continued with the proposed matrix solution table. The proposed table was summarized based on simulation results from general setting of the simulation shown in Table 1.

Table 1. Simulation Parameters High_Mobility_Speed

\begin{tabular}{|l|l|}
\hline Parameter & Value(s) \\
\hline Number of nodes & $10,20,30,40,50,60$ \\
\hline Simulation area & $\begin{array}{l}400 \times 400 \text { unit, } \\
600 \times 600 \text { unit, } \\
800 \times 800 \text { unit, } \\
1000 \times 1000 \text { unit }\end{array}$ \\
\hline Mobility model & $\begin{array}{l}\text { Random waypoint } \\
(0 \text { s pause time })\end{array}$ \\
\hline Node speed (maximum) & $22.2,11.1,1.0 \mathrm{~m} / \mathrm{s}$ \\
\hline Traffic type & Constant bit rate $(\mathrm{CBR})$ \\
\hline Traffic sending rate & 45,25, five packets per second \\
\hline Packet Size & 512 bytes \\
\hline Transmission range & 250 meters \\
\hline 802.11 MAC rate & 11 Mbps \\
\hline Simulation time & 150 seconds \\
\hline Number of simulation runs & 50 \\
\hline Number of nodes & $10,20,30,40,50,60$. \\
\hline
\end{tabular}

As mentioned earlier, the simulation for High_Mobility_Speed scenario has been set up with high mobility speed which is movement speed for each mobile nodes is determined as $22.2 \mathrm{~meter} / \mathrm{sec}$. All the simulation results for High_Mobility_Speed scenario is discussed in details in the following table. Table 2 interprets the energy usage values obtained for all cases under High_Mobility_Speed scenario. This table shows that the number of nodes that have a balance of energy has increased when the network space area increased. These results also show that higher data transmission rate will increase the energy used. This indicates that the number of dead nodes will decrease for a bigger network space area. 
International Journal of Mobile Network Communications \& Telematics (IJMNCT) Vol. 5, No.3, June 2015

Table 2. The energy usage values obtained for the all cases under High_Mobility_Speed

\begin{tabular}{|c|c|c|c|c|c|c|c|}
\hline \multirow{2}{*}{$\begin{array}{l}\text { Network } \\
\text { space area }\end{array}$} & \multirow{2}{*}{ Mobility Speed } & \multicolumn{6}{|c|}{ Energy usage } \\
\hline & & 10 & 20 & 30 & 40 & 50 & 60 \\
\hline \multirow{3}{*}{$\begin{array}{c}400 \times 400 \\
\text { unit }\end{array}$} & High & 999.998 & 1000 & 1000 & 1000 & 1000 & 1000 \\
\hline & Medium & 999.988 & 1000 & 1000 & 1000 & 1000 & 1000 \\
\hline & Low & 999.99 & 1000 & 1000 & 1000 & 1000 & 1000 \\
\hline \multirow{3}{*}{$\begin{array}{c}600 \times 600 \\
\text { unit }\end{array}$} & High & 999.998 & 999.995 & 999.999 & 1000 & 999.988 & 1000 \\
\hline & Medium & 1000 & 1000 & 999.964 & 999.997 & 1000 & 1000 \\
\hline & Low & 1000 & 999.981 & 999.98 & 999.976 & 999.992 & 1000 \\
\hline \multirow{3}{*}{$\begin{array}{c}800 \times 800 \\
\text { unit }\end{array}$} & High & 999.961 & 999.98 & 1000 & 999.992 & 999.985 & 999.99 \\
\hline & Medium & 999.921 & 999.965 & 999.989 & 999.992 & 999.995 & 999.982 \\
\hline & Low & 999.878 & 999.901 & 999.983 & 999.965 & 999.983 & 999.999 \\
\hline \multirow{3}{*}{$\begin{array}{c}1000 \times 1000 \\
\text { unit }\end{array}$} & High & 999.987 & 999.974 & 999.943 & 999.962 & 999.968 & 999.988 \\
\hline & Medium & 999.97 & 999.992 & 999.976 & 999.973 & 999.966 & 999.947 \\
\hline & Low & 999.189 & 999.98 & 999.932 & 999.978 & 999.965 & 999.96 \\
\hline
\end{tabular}

Table 3 summarizes the number of nodes that keep alive for all cases under High_Mobility_Speed scenario. The result shows that when the network space area increased, the number of nodes keeps alive is also increased. Similarly, when the number of nodes increased, the average number of live nodes will also be increased. The statement above has been illustrated as shown in Figure 1.

Table 3. The value of the number of nodes those keep alive High_Mobility_Speed

\begin{tabular}{|c|c|c|c|c|c|c|c|}
\hline Network & \multirow{2}{*}{ space area } & \multirow{2}{*}{ Mobility Speed } & \multicolumn{7}{|c|}{ Nodes keep alive } \\
\cline { 2 - 8 } & & 10 & 20 & 30 & 40 & 50 & 60 \\
\hline \multirow{3}{*}{$400 \times 400$} & High & 3 & 0 & 0 & 0 & 0 & 0 \\
\cline { 2 - 8 } & Medium & 4 & 0 & 0 & 0 & 0 & 0 \\
\cline { 2 - 8 } & Low & 4 & 0 & 0 & 0 & 0 & 0 \\
\hline \multirow{3}{*}{$600 \times 600$} & High & 2 & 1 & 1 & 0 & 4 & 0 \\
\cline { 2 - 8 } & Medium & 1 & 0 & 5 & 3 & 0 & 0 \\
\cline { 2 - 8 } & Low & 0 & 3 & 4 & 3 & 3 & 2 \\
\hline \multirow{3}{*}{$800 \times 800$} & High & 2 & 3 & 0 & 4 & 3 & 6 \\
\cline { 2 - 8 } & Medium & 3 & 5 & 4 & 3 & 3 & 7 \\
\cline { 2 - 8 } & Low & 4 & 10 & 3 & 7 & 5 & 1 \\
\hline \multirow{3}{*}{$1000 \times 1000$} & High & 1 & 3 & 3 & 9 & 6 & 5 \\
\cline { 2 - 8 } & Medium & 2 & 2 & 5 & 7 & 8 & 10 \\
\cline { 2 - 8 } & Low & 10 & 3 & 6 & 9 & 8 & 11 \\
\hline
\end{tabular}




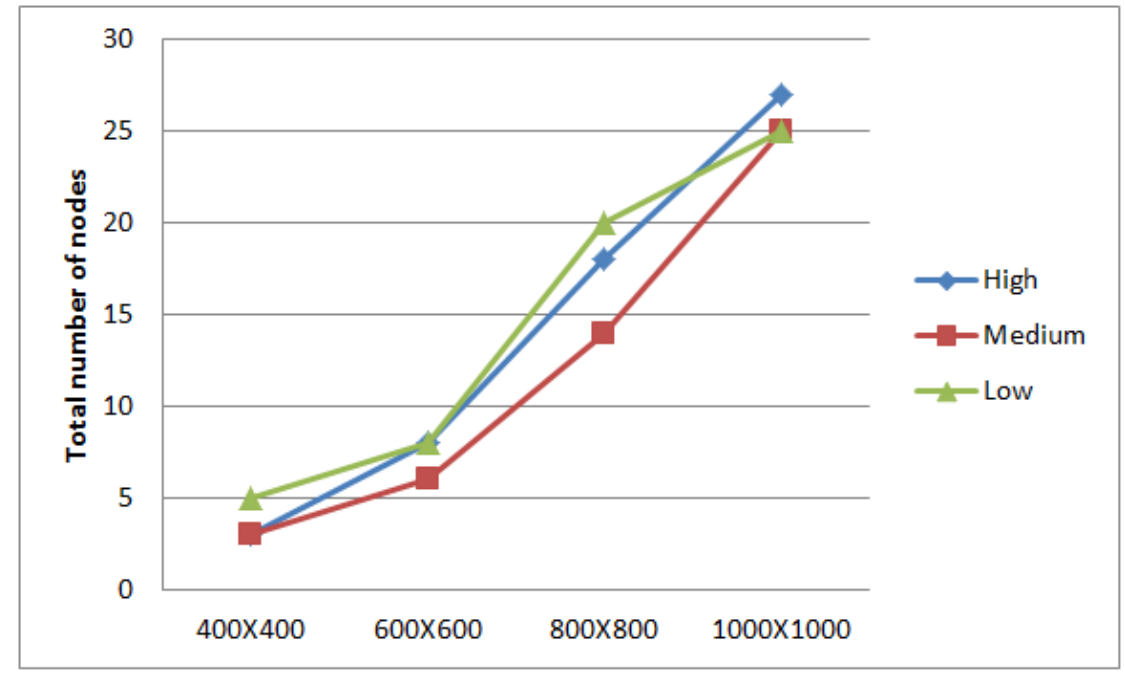

Figure 1. The total number of nodes keeps alive for high mobility speed with various data transmission rate

\subsection{High_Data_Transmission_Rate Scenario} for different space area

The High_Data_Transmission_Rate scenario has been set up using a high data transmission rate value of 45 packets/sec. In the following, we will discuss the simulation results for fixed setting of data transmission rate with various setting of network space and node speed.

Table 4 illustrates the energy usage values obtained for all cases under High_Data_Transmission_Rate scenario. It can be seen that the larger network space size will results in increasing number of nodes that have a balance of energy left. This indicates that the number of dead nodes will decrease with larger network space area.

Table 4. The energy usage values for all cases under High_Data_Transmission_Rate

\begin{tabular}{|c|c|c|c|c|c|c|c|}
\hline \multirow{2}{*}{$\begin{array}{l}\text { Network } \\
\text { space area }\end{array}$} & \multirow{2}{*}{\begin{tabular}{|c|} 
Data Transmission \\
Rate
\end{tabular}} & \multicolumn{6}{|c|}{ Energy usage } \\
\hline & & 10 & 20 & 30 & 40 & 50 & 60 \\
\hline \multirow{3}{*}{$\begin{array}{c}400 \times 400 \\
\text { unit }\end{array}$} & High & 999.998 & 1000 & 1000 & 1000 & 1000 & 1000 \\
\hline & Medium & 999.997 & 1000 & 1000 & 1000 & 1000 & 1000 \\
\hline & Low & 999.987 & 1000 & 1000 & 1000 & 1000 & 1000 \\
\hline \multirow{3}{*}{$\begin{array}{c}600 \times 600 \\
\text { unit }\end{array}$} & High & 999.998 & 999.995 & 999.999 & 1000 & 999.988 & 1000 \\
\hline & Medium & 999.994 & 1000 & 999.998 & 1000 & 999.997 & 1000 \\
\hline & Low & 999.989 & 999.997 & 999.997 & 1000 & 1000 & 1000 \\
\hline \multirow{3}{*}{$\begin{array}{c}800 \times 800 \\
\text { unit }\end{array}$} & High & 999.961 & 999.98 & 1000 & 999.992 & 999.985 & 999.99 \\
\hline & Medium & 999.949 & 999.969 & 1000 & 999.995 & 999.991 & 999.992 \\
\hline & Low & 999.973 & 999.967 & 999.964 & 999.998 & 999.99 & 999.99 \\
\hline \multirow{3}{*}{$\begin{array}{c}1000 \times 1000 \\
\text { unit }\end{array}$} & High & 999.987 & 999.974 & 999.943 & 999.962 & 999.968 & 999.988 \\
\hline & Medium & 999.993 & 999.966 & 999.943 & 999.971 & 999.97 & 999.99 \\
\hline & Low & 999.99 & 999.953 & 999.745 & 999.998 & 999.973 & 999.985 \\
\hline
\end{tabular}

Table 5 illustrates the entire values for the number of nodes that still keeps alive for all cases under High_Data_Transmission_Rate scenario. From the table, it shows that when the number of nodes increases, the average number of live nodes will also increase for $1000 \times 1000$ unit space area for the entire different data transmission rate (high, medium and low) except for node 10 at low data transmission. The results also show that when the network space area increases, the 
number of node alive also increases. Similarly, when we increased data transmission rate, the number of nodes that alive will be increase except for the node 10 at space $400 \mathrm{X} 400$ and $600 \times 600$ unit, 50 node at $600 \times 600$ unit, and 60 node at $800 \times 800$ unit will decrease. The statement above has been described as shown in Figure 2.

Table 5. The value for the nodes number those keep alive High_Data_Transmission_Rate

\begin{tabular}{|c|c|c|c|c|c|c|c|}
\hline \multirow{2}{*}{$\begin{array}{c}\text { Network } \\
\text { space area }\end{array}$} & $\begin{array}{c}\text { Data Transmission } \\
\text { Rate }\end{array}$ & \multicolumn{7}{|c|}{ Nodes keep alive } \\
\cline { 2 - 8 } & High & 3 & 20 & 30 & 40 & 50 & 60 \\
\hline \multirow{3}{*}{$400 \times 400$} & Medium & 3 & 0 & 0 & 0 & 0 & 0 \\
\cline { 2 - 8 } & Low & 5 & 0 & 0 & 0 & 0 & 0 \\
\cline { 2 - 8 } & High & 2 & 1 & 1 & 0 & 4 & 0 \\
\hline \multirow{3}{*}{$800 \times 600$} & Medium & 3 & 0 & 1 & 0 & 2 & 0 \\
\cline { 2 - 8 } & Low & 5 & 2 & 1 & 0 & 0 & 0 \\
\cline { 2 - 8 } & High & 2 & 3 & 0 & 4 & 3 & 6 \\
\cline { 2 - 8 } & Medium & 2 & 3 & 1 & 2 & 2 & 4 \\
\cline { 2 - 8 } & Low & 2 & 3 & 5 & 3 & 4 & 3 \\
\hline \multirow{3}{*}{$1000 \times 1000$} & High & 1 & 3 & 3 & 9 & 6 & 5 \\
\cline { 2 - 8 } & Medium & 2 & 2 & 3 & 8 & 6 & 4 \\
\cline { 2 - 8 } & Low & 2 & 4 & 4 & 1 & 7 & 7 \\
\hline
\end{tabular}

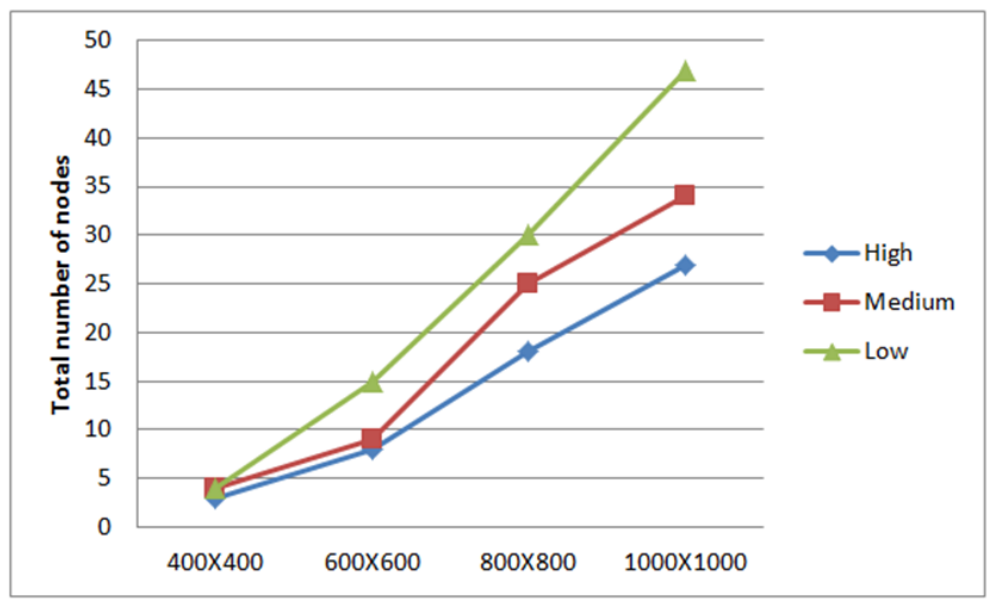

Figure 2. The total number of nodes keeps alive for high data transmission rate with various mobility speeds for different space area

\section{Matrix Solution Table}

This section will discuss the proposed matrix solution table which is come out based on summarization from the results from all cases of High_Mobility_Speed and High_Data_Transmission_Rate scenario. These comprehensive tables will help to plan in more efficient network management. 
Table 5. The Matrix Solution for High Speed of Mobility.

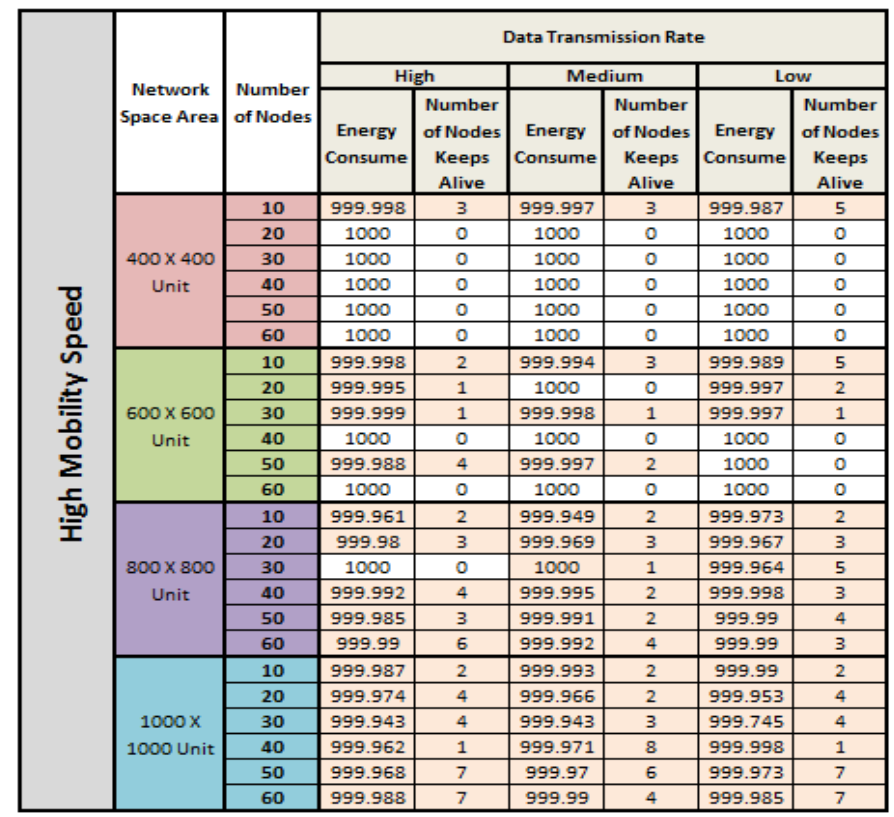

Table 5 shows the matrix solution for all element involved energy usage and number of nodes keep alive for high, medium and low data transmission rate, for a number of nodes 10 to 60 at 400X400, 600X600, 800X800, and 1000X1000 unit space for high speed of mobility. For example, to send using high mobility speed at the high data transmission rate (critical), we can choose either 400X400 unit (for node 10), 600X600 unit (for node 10, 20, 30, and 50), 800X800 unit ( for all nodes except 30 node) and 1000X1000 unit (for all nodes).

Table 6. The Matrix Solution for High Data Transmission Rate

\begin{tabular}{|c|c|c|c|c|c|c|c|c|}
\hline \multirow{27}{*}{ 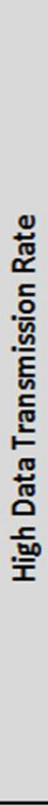 } & \multirow{3}{*}{$\begin{array}{c}\text { Network } \\
\text { Space Area }\end{array}$} & \multirow{3}{*}{$\begin{array}{l}\text { Number } \\
\text { of Nodes }\end{array}$} & \multicolumn{6}{|c|}{ Mobility Speed } \\
\hline & & & \multicolumn{2}{|c|}{ High } & \multicolumn{2}{|c|}{ Medium } & \multicolumn{2}{|c|}{ Low } \\
\hline & & & $\begin{array}{l}\text { Energy } \\
\text { Consume }\end{array}$ & $\begin{array}{c}\begin{array}{c}\text { Number } \\
\text { of Nodes } \\
\text { Keeps } \\
\text { Alive }\end{array} \\
\end{array}$ & $\begin{array}{l}\text { Energy } \\
\text { Consume }\end{array}$ & $\begin{array}{c}\begin{array}{c}\text { Number } \\
\text { of Nodes } \\
\text { Keeps } \\
\text { Alive }\end{array} \\
\end{array}$ & $\begin{array}{c}\text { Energy } \\
\text { Consume }\end{array}$ & $\begin{array}{c}\text { Number } \\
\text { of Nodes } \\
\text { Keeps } \\
\text { Alive } \\
\end{array}$ \\
\hline & \multirow{6}{*}{$\begin{array}{c}400 \times 400 \\
\text { Unit }\end{array}$} & 10 & \begin{tabular}{|l}
999.998 \\
\end{tabular} & 3 & \begin{tabular}{|l|}
999.988 \\
\end{tabular} & 4 & 999.99 & 4 \\
\hline & & 20 & 1000 & 0 & 1000 & 0 & 1000 & 0 \\
\hline & & 30 & 1000 & 0 & 1000 & 0 & 1000 & 0 \\
\hline & & 40 & 1000 & 0 & 1000 & 0 & 1000 & 0 \\
\hline & & 50 & 1000 & 0 & 1000 & 0 & 1000 & 0 \\
\hline & & 60 & 1000 & 0 & 1000 & 0 & 1000 & 0 \\
\hline & \multirow{6}{*}{$\begin{array}{c}600 \times 600 \\
\text { Unit }\end{array}$} & 10 & \begin{tabular}{|l}
999.998 \\
\end{tabular} & 2 & 1000 & 1 & 1000 & 0 \\
\hline & & 20 & 999.995 & 1 & 1000 & 0 & 999.981 & 3 \\
\hline & & 30 & \begin{tabular}{|l}
999.999 \\
\end{tabular} & 1 & \begin{tabular}{|l|}
999.964 \\
\end{tabular} & 5 & 999.98 & 4 \\
\hline & & 40 & 1000 & 0 & \begin{tabular}{|l|}
999.997 \\
\end{tabular} & 3 & 999.976 & 3 \\
\hline & & 50 & \begin{tabular}{|l}
999.988 \\
\end{tabular} & 4 & 1000 & 0 & 999.992 & 3 \\
\hline & & 60 & 1000 & 0 & 1000 & 0 & 1000 & 2 \\
\hline & \multirow{6}{*}{$\begin{array}{c}800 \times 800 \\
\text { Unit }\end{array}$} & 10 & 999.961 & 2 & 999.921 & 3 & 999.878 & 4 \\
\hline & & 20 & 999.98 & 3 & \begin{tabular}{|l}
999.965 \\
\end{tabular} & 5 & 999.901 & 10 \\
\hline & & 30 & 1000 & 0 & \begin{tabular}{|l|}
999.989 \\
\end{tabular} & 4 & 999.983 & 3 \\
\hline & & 40 & 999.992 & 4 & 999.992 & 3 & 999.965 & 7 \\
\hline & & 50 & 999.985 & 3 & 999.995 & 3 & 999.983 & 5 \\
\hline & & 60 & 999.99 & 6 & \begin{tabular}{|l}
999.982 \\
\end{tabular} & 7 & \begin{tabular}{|l|}
999.999 \\
\end{tabular} & 1 \\
\hline & \multirow{6}{*}{$\begin{array}{c}1000 \mathrm{x} \\
1000 \text { Unit }\end{array}$} & 10 & 999.987 & 1 & 999.97 & 2 & 999.189 & 10 \\
\hline & & 20 & \begin{tabular}{|l}
999.974 \\
\end{tabular} & 3 & \begin{tabular}{|l|}
999.992 \\
\end{tabular} & 2 & 999.98 & 3 \\
\hline & & 30 & 999.943 & 3 & \begin{tabular}{|l|}
999.976 \\
\end{tabular} & 5 & 999.932 & 6 \\
\hline & & 40 & 999.962 & 9 & \begin{tabular}{|l}
999.973 \\
\end{tabular} & 7 & 999.978 & 9 \\
\hline & & 50 & 999.968 & 6 & 999.966 & 8 & 999.965 & 8 \\
\hline & & 60 & 999.988 & 5 & 999.947 & 10 & 999.96 & 11 \\
\hline
\end{tabular}

Table 6 illustrate the matrix solution for high data transmission rate involves the element of energy usage and number of nodes keep alive for high, medium and low speed of the mobility, for the number of nodes 10 to 60 at unit space of $400 \mathrm{X} 400,600 \mathrm{X} 600,800 \mathrm{X} 800$, and $1000 \mathrm{X} 1000$ 
unit. This matrix solution that stated in Table 5 and Table 6 has proposed as a guideline in order to select the suitable element for the scenario that they want to set up for their research.

\section{CONCLUSION}

Conclusively, the results of the reports and analysis on the OLSR simulation scenario shows that the network elements or parameters such as number of nodes, the size of the network space, the mobility speed and data transmission rate will effects energy usage of each node in the network and the number of nodes keep alive. The end of this simulation scenario was proposed a new energy matrix based on the energy usage and the optimum numbers of nodes keep alive in networks with high mobility speed and high data transmission rate. This new energy matrix will used to design a suitable mobile network for specific purpose which is the energy usage will consider. This matrix solution table help researcher or decision maker to find the best value for each element to manage their network more efficiently.

\section{REFERENCES}

[1] Utkarsh, Mishra M \& Chinara S, (2012) "ESAR: An energy saving ad hoc routing algorithm for MANET", 4th International Conference on Advanced Computing, ICoAC 2012.

[2] Bellavista P, Cardone G, Corradi A \& Foschini L. (2013). "Convergence of MANET and WSN in IoT urban scenarios". IEEE Sensors Journal, 13(10), pp.3558-3567.

[3] Mahfoudh S, \& Minet P. (2008). "An Energy Efficient Routing Based on OLSR in Wireless Ad Hoc and Sensor Networks". 22nd International Conference on Advanced Information Networking and Applications - Workshops (aina Workshops 2008), pp.1253-1259.

[4] Hwang CJ, Kush A, \& Taneja S. (2011). "Making MANET energy efficient", 2011 Global Mobile Congress, GMC 2011.

[5] Ray, S. (2003). Realistic Mobility for MANET Simulation. Engineering, (December)

\section{Authors}

Suhazlan Suhaimi is a lecturer in the Faculty of Art, Computing and Creative Industry at Sultan Idris Educational University (UPSI), Malaysia. He obtained his BSc in Computer (Networking) (2003), from University Putra Malaysia (UPM), MSc in Information Technology (2008), from Malaysia University of Science and Technology (MUST), Malaysia. His working experience more than ten years in Institutions of Higher Learning. His areas of interests includes Computer Science, Computer Networking.

Dr. Kamaruddin Mamat is a senior lecturer in the Faculty of Computer and Mathematical Sciences at University Teknology MARA (UiTM), Malaysia. He obtained his BSc (Hons) in Statistics (1985), from National University of Malaysia (UKM), MSc in Computer Science (1987), from Western Michigan University (WMU), USA and PhD in Multimedia Network (2007) from Sultan Idris Education University (UPSI), Malaysia. His working experience more than twenty-five years in Institutions of Higher Learning. His areas of interests includes Computer Science, Computer Networking, and Computer Security. 